\title{
Stabilization of molybdenum by alternative cementitious binders and synthetic C-S-H
}

\author{
DR. LAURA DIAZ CASELLES, PHD, CÉDRIC ROOSZ, \\ JULIE HOT, SIMON BLOTEVOGEL AND MARTIN CYR \\ LMDC, INSA/UPS Génie Civil
}

Presenting Author: diazcase@insa-toulouse.fr

The release of molybdenum (Mo) from soils and sediments is a serious concern leading to risks for both human health and the environment. This study focuses on the immobilization of Mo by three cementitious binders and examines the mechanisms of Mo stabilization. To this end, one Ordinary Portland cement (OPC) (reference material), one binder composed of $90 \%$ ground granulated blast furnace slag (GGBS) and $10 \%$ OPC (referred to as 90-10) and one supersulfated GGBS cement were spiked with sodium molybdate at six different Mo concentrations from 0.005 to $10 \mathrm{wt} \%$ Mo ( $\%$ by weight of anhydrous binder). After hydration, the mobility of Mo was evaluated by a leaching test. In a next step, calcium silicate hydrates (C-S-H) were synthesized in the presence of Mo (from 0.25 to $5 \mathrm{wt} \% \mathrm{Mo}$ ) in order to evaluate their contribution to the immobilization of Mo. To identify the mechanisms of Mo stabilization, all solid samples were analyzed using X-ray diffraction (XRD), Fourier-Transform Infrared Spectroscopy (FT-IR), thermogravimetric (TGA) analyses and Scanning Electron Microscopy with Energy Dispersive Spectroscopy (SEM/EDS). Mo and major element concentrations in leachates and solutions after paste leaching tests and C-S-H syntheses were determined by using Inductively Coupled Plasma Atomic Emission Spectrometry (ICP-AES). Thermodynamic calculations using the PHREEQC code were used to study the immobilization of Mo at low Mo concentrations $\left(<300 \mathrm{mg}_{\mathrm{Mo}} / \mathrm{kg}_{\text {solid }}\right.$ ).

It was found that Mo retention depended on the initial Mo concentration and varied from one binder to another. At high Mo concentrations $(5 \mathrm{wt} \%)$, the precipitation of powellite $\left(\mathrm{CaMoO}_{4}\right)$ was found to be the dominant mechanism controlling Mo retention. At lower Mo concentrations $(<1 \mathrm{wt} \%)$, Mo was found near sulfates probably due to substitution or adsorption of Mo on sulfate-bearing phases. Moreover, it was found that Mo was largely immobilized (>95\%) in all the synthetic C-S-H phases and the main mechanism of Mo stabilization was the coprecipitation of powellite. Thermodynamic modeling showed that powellite only precipitated at Mo concentrations superior to $90 \mathrm{mg}_{\mathrm{Mo}} / \mathrm{kg}_{\text {binder }}$. 